\title{
Commentary
}

SLE

\section{Hematopoietic stem cell transplantation for systemic lupus erythematosus}

\author{
Richard K Burt and Ann E Traynor \\ Division of Immunotherapy, Northwestern University School of Medicine, Chicago, Illinois, USA \\ Correspondence: Richard K Burt (e-mail: rburt@nwu.edu)
}

Received: 5 Mar 2003 Accepted: 27 May 2003 Published: 26 Jun 2003

Arthritis Res Ther 2003, 5:207-209 (DOI 10.1186/ar786)

(c) 2003 BioMed Central Ltd (Print ISSN 1478-6354; Online ISSN 1478-6362)

\begin{abstract}
Hematopoietic stem cell transplantation was first reported for patients with systemic lupus erythematosus in 1997. The procedure has since been performed worldwide including in Europe, in Brazil, and in China. A National Institutes of Health-funded phase III clinical trial of hematopoietic stem cell transplantation for refractory systemic lupus erythematosus is anticipated to begin in 2003. Encouraging responses are raising new hope about the role of adult hematopoietic stem cells in systemic lupus erythematosus.
\end{abstract}

Keywords: hematopoietic stem cell transplantation, lupus

\section{Introduction}

The prognosis of systemic lupus erythematosus (SLE) markedly improved following the introduction of monthly intravenous pulse cyclophosphamide $\left(500-1000 \mathrm{mg} / \mathrm{m}^{2}\right)$. Nevertheless, despite pulse cyclophosphamide and advances in supportive care such as new antihypertensive medications, patients with active SLE involving visceral organs have 2-year and 5-year mortalities of approximately $20 \%$ and $35 \%$, respectively. Since SLE is predominately a disease of young women, improvements in disease-related morbidity and mortality were desperately needed.

Autologous hematopoietic stem cell transplant regimens for patients with cancer are based on dose escalation of chemotherapeutic drugs that demonstrate effectiveness at standard dosing. Borrowing this concept from the field of oncology, we dose escalated cyclophosphamide, the most effective antilupus medication, to $200 \mathrm{mg} / \mathrm{kg}$. Also borrowing from experience with a hematopoietic stem cell transplantation (HSCT) conditioning regimen for aplastic anemia, where Tlymphocytes help to sustain the disease manifestations, a regimen of $200 \mathrm{mg} / \mathrm{kg}$ cyclophosphamide (divided as $50 \mathrm{mg} / \mathrm{kg}$ over 4 days) and of
$90 \mathrm{mg} / \mathrm{kg}$ equine antithymocyte globulin (ATG) (divided as $30 \mathrm{mg} / \mathrm{kg}$ over 3 days) was selected.

To collect hematopoietic stem cells, they need to be mobilized into the peripheral blood with either a hematopoietic colony stimulating factor such as granulocyte-colony stimulating factor or a chemotherapeutic drug such as cyclophosphamide, or both. Since granulocyte-colony stimulating factor is a proinflammatory cytokine that by itself may exacerbate disease, the stem cells were mobilized into the peripheral blood using $2.0 \mathrm{~g} / \mathrm{m}^{2}$ cyclophosphamide, granulocyte-colony stimulating factor beginning 72 hours later, and harvest beginning upon white blood cell rebound (usually 10 days after cyclophosphamide). The stem cells are collected on an outpatient basis by apheresis and then purified in the laboratory by positive selection using an antibody to CD34, a progenitor cell antigen, resulting in a 4-log depletion of lymphocytes.

Continuing the analogy to malignancies, HSCT is generally effective if the cancer is still responsive to chemotherapy but is ineffective when applied to chemotherapy refractory disease. Lupus is an immune responsive 
disease that, when refractory to oral daily cyclophosphamide, responds to dose escalation with intravenous monthly cyclophosphamide. It was anticipated that SLE, refractory to monthly pulse cyclophosphamide, might respond to further dose escalation of cyclophosphamide and HSCT. These expectations were realized and patients with refractory disease have entered sustained freedom from immune suppression for up to 6 years following HSCT [1-6]. Of 20 patients followed for between 6 months and 6 years post HSCT at Northwestern University, only one is taking more than $10 \mathrm{mg} /$ day prednisone.

There are unique aspects to SLE compared with malignancies or other autoimmune diseases treated by HSCT. Lupus patients are often exposed to chronic high-dose corticosteroids and are consequently diabetic, hyperlipidemic, osteoperotic, hypertensive, susceptible to coronary artery disease, susceptible to avascular necrosis and susceptible to opportunistic infections. Patients should be screened for cardiac symptoms, for avascular necrosis and for occult infection prior to registration. In addition, aggressive antiviral, fungal and bacterial coverage is initiated during any period of neutropenia independent of fever. After HSCT, as corticosteroids are gradually withdrawn, the disease becomes quiescent, SLE-associated immune abnormalities slowly resolve and the risk of infection, a common cause of death for patients with SLE, returns to that of normal healthy controls. Improvement generally occurs gradually over 6-12 months and an aggressive corticosteroid taper may precipitate disease flare during this interval.

Organ dysfunction, such as renal or pulmonary insufficiency, is considered a contraindication for HSCT among patients with malignancies. For patients with SLE, in contrast, since organ compromise is due to lupus, impaired visceral organ function is not necessarily a contraindication, and may even be the major indication for HSCT. While this makes the transplant procedure more complicated, marked organ improvement, particularly of the lung, the kidney and the central nervous system, has occurred following HSCT. Patients with nephritis are unusually susceptible to electrolyte disturbances and to volume overload, which may lead to pulmonary edema and to respiratory failure unless early dialysis is initiated. Pharmacokinetics of drugs such as high cyclophosphamide metabolites are poorly understood in patients with renal failure. For this reason, in patients with either renal insufficiency or renal failure, dialysis is performed each morning after a cyclophosphamide infusion the preceding day.

Besides tapering off immune suppressive medications, prior to HSCT, some patients required multiple antihypertensive medications, most of which have also been gradually tapered following transplant. Improvement in end-organ function has demonstrated remarkable would not be expected to reverse, proteinuria resolves and some patients become dialysis free. Pulmonary function tests including both forced vital capacity and diffusion capacity gradually improve. Several patients became free of supplemental inspired oxygen for the first time in several years. Serologic measures associated with disease such as hypocomplementemia, antidouble-stranded DNA, and antinuclear antibodies normalize. Detection of low titer antinuclear antibody positivity in the years following transplant seldom predicts reactivation of disease.

With a cyclophosphamide/ATG regimen, hematopoietic stem cells are not necessary for re-engraftment. While intensely immune suppressive, the regimen is not myeloablative and endogenous hematopoiesis would recover. The hematopoietic stem cells are infused in order to shorten the past transplant neutropenic interval by 4-6 days compared with the same dose of cyclophosphamide without hematopoietic stem cell support, and also to hasten stem cell regeneration of the immune system under the umbrella of the ATG effect.

Based on the same rationale, Brodsky and colleagues at Johns Hopkins have dose escalated cyclophosphamide to $200 \mathrm{mg} / \mathrm{kg}$ without ATG or HSCT [7]. Whether transplant doses of cyclophosphamide are given with or without hematopoietic stem cell support, impressive responses are occurring. It is currently impossible to contrast the two approaches since SLE is a clinically heterogeneous disease and entry criteria between the two studies are different $[3,6,7]$. The Hopkins approach has included some patients never treated with cyclophosphamide and other patients previously treated with only oral cyclophosphamide [7]. The Northwestern HSCT study required failure of intravenous cyclophosphamide (i.e. active disease requiring treatment) after a minimum of 3-6 consecutive months of cyclophosphamide [2-6]. Both the Hopkins and the Northwestern protocols are based on dose escalation of cyclophosphamide. However, due to mobilization of stem cells with $2.0 \mathrm{mg} / \mathrm{m}^{2}$ (approximately $55 \mathrm{mg} / \mathrm{kg}$ ) cyclophosphamide 2-4 weeks prior to HSCT, patients on the HSCT protocol receive a total cyclophosphamide dose of $255 \mathrm{mg} / \mathrm{kg}$, compared with $200 \mathrm{mg} / \mathrm{kg}$ in the study of Brodsky and colleagues. By having to mobilize stem cells, the transplant protocol allows for infusion of a significantly higher total cyclophosphamide dose (along with ATG), resulting in significantly more intense immune suppression.

For the laboratory immunologist, tolerance is defined as antigen-specific unresponsiveness. For the clinician, tolerance is lack of disease manifestations while off immune suppressive medications with normally intact third-party responses. Autologous HSCT appears to be reintroducing self-tolerance accompanied with a restoration of immune diversity, although the exact pathway(s) (e.g. T regulatory 
cells, deletion, etc.) are yet to be determined. Two philosophical approaches that do not really define the mechanisms involved in tolerance exist towards autologous HSCT of autoimmune diseases. One approach is 'immune ablation', advocated by the Seattle Consortium [8]. Advocates of 'immune ablation' use the terminology high-dose immune suppressive therapy. In this view, every potentially autoreactive lymphocyte is pathologic.

The alternative concept is one of immune 'reset' or immune 'balance' [5]. In this notion, autoreactive cells may be viewed as potentially 'normal'. During development, $T$ cells that bind a self-epitope with high avidity undergo apoptosis [9-11]. However, T cells that fail to recognize a self-epitope also undergo apoptosis [9-11]. Therefore, circulating $T$ cells in a healthy person normally possess a T-cell receptor repertoire selected to a self-epitope. Immune cells may be viewed as a dynamic equilibrium that maintains steady state by constantly fluctuating between tolerance and immunity. This dynamic state is best demonstrated by the intermittent clinical course of some autoimmune diseases such as relapsing-remitting multiple sclerosis, which flares and remits spontaneously even without treatment. Using the notion of immune balance, the conditioning regimen is not intended to destroy every immune cell, but rather is intended to be sufficient to restore immune 'balance'.

In practice, the philosophy of high-dose immune suppressive therapy leads to maximal immune suppressive regimens that have been accompanied by infection-related mortality as well as regimen-related mortality [12]. In comparison, the notion of immune balance leads to less intense regimens that are more easily tolerated and have less infection-related risk. Whether one concept or the other is correct remains unclear. There is currently no data to support more intense regimens over less toxic regimens in terms of disease remission or relapse rate. The appropriate regimen intensity may vary by disease. For example, cyclophosphamide with or without ATG appears inadequate for complete responses or sustained untreated partial responses in rheumatoid arthritis $[13,14]$. Yet this same regimen appears highly effective in SLE [2-6]. Whatever the most appropriate concept for a given disease, it is probably prudent to determine outcome with less intense regimens before testing more intense, and potentially more toxic, conditioning regimens.

\section{Conclusion}

Future studies are being planned to confirm the efficacy of HSCT for SLE as well as to better understand the mechanisms of disease remission. A National Institutes of Healthfunded phase III trial comparing HSCT with pulse intravenous cyclophosphamide is in development. If HSCT is the more effective therapy, the next phase III trial may be a direct comparison of HSCT with cyclophosphamide and
ATG versus the Hopkins' treatment protocol incorporating high-dose cyclophosphamide without stem cell support.

\section{Competing interests}

None declared.

\section{References}

1. Marmont AM, van Lint MT, Gualandi F, Bacigalupo A: Autologous marrow stem cell transplantation for severe systemic lupus erythematosus of long duration. Lupus 1997, 6:545-548.

2. Burt RK, Traynor A, Ramsey-Goldman R: Hematopoietic stemcell transplantation for systemic lupus erythematosus. $N$ Engl $J$ Med 1997, 337:1777-1778.

3. Traynor AE, Schroeder J, Rosa RM, Cheng D, Stefka J, Mujais S, Baker S, Burt RK: Treatment of severe systemic lupus erythematosus with high-dose chemotherapy and haemopoietic stem-cell transplantation: a phase I study. Lancet 2000, 356: 701-707.

4. Traynor A, Burt RK: Haematopoietic stem cell transplantation for active systemic lupus erythematosus. Rheumatology 1999 , 38:767-772.

5. Burt RK, Slavin S, Burns WH, Marmont A: Induction of tolerance in autoimmune disease by hematopoietic stem cell transplantation: getting closer to a cure? Blood 2002, 99:870-887.

6. Traynor AE, Barr WG, Rosa RM, Rodriquez J, Oyama Y, Baker S, Brush M, Burt RK: Hematopoietic stem cell transplantation for severe and refractory lupus. Analysis after five years and fifteen patients. Arthritis Rheum 2002, 46:2917-2923.

7. Brodsky RA, Petri M, Smith BD, Steifter J, Spivak JL, Styler M, Dang CV, Bridsky I, Jones R: Immunablative high dose cyclophosphamide without stem cell rescue for refractory severe autoimmune disease. Ann Intern Med 1998, 129:1031-1035.

8. McSweeney PA, Nash RA, Sullivan KM, Storek J, Crofford LJ, Dansey R, Mayes MD, McDonagh KT, Nelson JL, Gooley TA, Holmberg LA, Chen CS, Wener MH, Ryan K, Sunderhaus J, Russell K, Rambharose J, Storb R, Furst DE: High-dose immunosuppressive therapy for severe systemic sclerosis: initial outcomes. Blood 2002, 100:1602-1610.

9. Bevan MJ, Hogquist KA, Jameson SC: Selecting the T cell receptor repertoire. Science 1994, 264:796-797.

10. Ashton-Rickardt PG, Tonegawa S: A differential-avidity model for T-cell selection. Immunol Today 1994, 15:362-366.

11. Sebzda E, Wallace VA, Mayer J, Yeung RS, Mak TW, Ohashi PS: Positive and negative thymocyte selection induced by different concentrations of a single peptide. Science 1994, 263: 1615-1618.

12. Tyndall A, Fassas A, Passweg J, Ruiz de Elvira C, Attal M, Brooks P, Black C, Durez P, Finke J, Forman S, Fouillard L, Furst D, Holmes J, Joske D, Jouet J, Kotter I, Locatelli F, Prentice H, Marmont AM, McSweeney P, Musso M, Peter HH, Snowden JA, Sullivan K, Gratwohl A, et al:: Autologous haematopoietic stem cell transplants for autoimmune disease - feasibility and transplant-related mortality. Autoimmune Disease and Lymphoma Working Parties of the European Group for Blood and Marrow Transplantation, the European League Against Rheumatism and the International Stem Cell Project for Autoimmune Disease. Bone Marrow Transplant 1999, 24:729-734.

13. Burt RK, Georganas C, Schroeder J, Traynor A, Stefka J, Schuening F, Graziano F, Mineishi S, Brush M, Fishman M, Welles C, Rosen S, Pope R: Autologous hematopoietic stem cell transplantation in refractory rheumatoid arthritis - sustained response in two of four patients. Arthritis Rheum 1999, 42: 2281-2285.

14. Moore J, Brooks P, Milliken S, Biggs J, Ma D, Handel M, Cannell P, Will R, Rule S, Joske D, Langlands B, Taylor K, O'Callaghan J, Szer J, Wicks I, McColl G, Passeullo F, Snowden J: A pilot randomized trial comparing CD34-selected versus unmanipulated hemopoietic stem cell transplantation for severe, refractory rheumatoid arthritis. Arthritis Rheum 2002, 46:2301-2309.

\section{Correspondence}

Richard K Burt, Division of Immunotherapy, Northwestern University School of Medicine, 320 East Superior, Room 3-489, Chicago, IL 60611, USA. Tel: +1 312908 0059; fax: +1 312908 0064; e-mail: rburt@nwu.edu 